Reihe

Germanistische

Linguistik

163

Herausgegeben von Helmut Henne, Horst Sitta und Herbert Ernst Wiegand 

Gustav Muthmann

\section{Phonologisches Wörterbuch der deutschen Sprache}

Max Niemeyer Verlag Tübingen 1996 
Die Deutsche Bibliothek - CIP-Einheitsaufnahme

\section{Muthmann, Gustav:}

Phonologisches Wörterbuch der deutschen Sprache / Gustav Muthmann. Tübingen : Niemeyer, 1996

(Reihe Germanistische Linguistik ; 163)

NE: HST; GT

\section{ISBN 3-484-31163-0 ISSN 0344-6778}

(C) Max Niemeyer Verlag GmbH \& Co. KG, Tübingen 1996

Das Werk einschließlich aller seiner Teile ist urheberrechtlich geschützt. Jede Verwertung außerhalb der engen Grenzen des Urheberrechtsgesetzes ist ohne Zustimmung des Verlages unzulässig und strafbar. Das gilt insbesondere für Vervielfältigungen, Übersetzungen, Mikroverfilmungen und die Einspeicherung und Verarbeitung in elektronischen Systemen. Printed in Germany.

Gedruckt auf alterungsbeständigem Papier.

Druck: Weihert-Druck GmbH, Darmstadt

Buchbinder: Industriebuchbinderei Hugo Nädele, Nehren 